\title{
Conducting a European multi-center trial: first experiences with the new EU Clinical Trials Directive from an academic perspective
}

\author{
Diyar Delawi · Wouter J. A. Dhert • \\ F. Cumhur Oner
}

Received: 28 February 2008/Accepted: 25 May 2008/Published online: 13 June 2008

(C) The Author(s) 2008

\section{Introduction}

In 2001 the European Union adopted the EU Clinical Trials Directive (2001/20/EC) as a framework for good management in trials of medicines [4]. Many concerns were expressed that this Directive would impede and inhibit publicly funded clinical trials $[2,7,14]$.

The question is if the concerns regarding the Clinical Trials Directive were legitimate. In other words, has the Directive really made it practically impossible for a group of surgeons to initiate, organize and conduct a European multi-center study? But also, has the new Directive achieved the goal of simplifying and harmonizing the administrative provisions governing clinical trials in EU countries?

As a University Medical Center, we have experienced the practical consequences of the Clinical Trials Directive at first hand during a European multi-center study on instrumented lumbar spinal fusions with the use of Osteogenic Protein-1 (OP-1). The objective of this paper is to provide insight in the difficulties involved while conducting such a European multi-center study under the new EU Clinical Trials Directive.

\section{Delawi · W. J. A. Dhert · F. C. Oner $(\bowtie)$}

Department of Orthopaedics, University Medical Center Utrecht, P.O. Box 85500, G05.228, 3508 GA Utrecht, The Netherlands e-mail: f.c.oner@umcutrecht.nl

\section{Delawi}

e-mail: d.delawi@umcutrecht.nl

W. J. A. Dhert

e-mail: w.dhert@umcutrecht.nl

\section{Background}

The reason for implementation of the Clinical Trial Directive was that the rules and requirements concerning clinical trials diverged considerably in the Member States, resulting in delays and complications detrimental to the effective conduct of European trials in the Community. It was therefore necessary to simplify and harmonize the administrative provisions governing such trials by establishing a clear, transparent procedure and creating conditions conducive to effective coordination of such trials.

Most objections to this directive were based on the conception that the Directive was conceived as a way of facilitating commercial drug development and that publicly funded trials were forced to fulfill the same requirements as their commercial counterparts [2]. The new requirements would impose a much greater administrative burden to independent and academic clinical research. Several articles addressed the essential role of independent research and expressed concerns about the increasing influence of industrial funding $[1,3,9]$. The research agenda can in this way be dictated by commercial profit only and thereby neglect research considered economically uninteresting [9, $10,12]$. These are real concerns as the objectivity of industry-driven trials have been frequently disputed $[3,5,6$, 11]. Out of concern for the future of academic research after the implementation of the new Directive, the "Save European Research" campaign was started, calling on the European Commission to repeal its Directive [8]. Despite the lobbying towards the policymakers to appreciate the role of non-commercial research, the European Union decided that the Directive must be incorporated into the national legislation in each Member State before May 2004.

Since our institution was responsible for the initiation and management of this aforementioned trial, we were, 
according to the definition of the Directive, considered 'the sponsor' of the trial. In this role we were one of the first academic centers to be faced with direct consequences of the new Directive in the perspective of a European multi-center clinical trial. The participants of this study initially consisted of spinal surgeons of 12 hospitals located in Germany, the Netherlands, Spain, France, United Kingdom and Italy. During the course of this study we ran into a great deal of anticipated as well as unanticipated difficulties.

\section{Encountered problems}

Although the EU Member States were required to have implemented the Directive by May 2004, not all Member States were able to transpose the Directive in their national legislation by this date. As a consequence, we were obliged to fulfill the new guidelines of the Directive for some of participating centers, while for other centers their original national requirements were still applicable. Due to this dichotomy in requirements, the responsibilities and obligations of our hospital, as the initiator and coordinator of the study, were not completely clear, not even to the Ethic Committees or Competent Authorities involved.

The Directive and implementing guidelines imposed many administrative requirements that did not exist, or were not similarly developed in the Member States [13]. This included an obligatory new Database (EUDRACT), an authorization request to the competent authorities, as well as an Investigational Medicinal Product Dossier; annual reports for clinical trials; adverse reaction reports and final study reports. The Clinical Trials Directive also introduced Good Clinical Practice (GCP) principles to ensure that trials are conducted in accordance with high standards of ethics and science. Although the practice of GCP were standard in all Member States, only a minority of Member States had previously codified the obligations of the different parties and the involvement of the competent authorities as now imposed by the Directive. GCP is a standard for the design, conduct, monitoring, analyses, and reporting of clinical trials that provides assurance that the data and reported results are credible and accurate and that the rights of trial subjects are protected. The requirements of GCP are noted in a 53 pages containing manual describing practices, responsibilities and actions of all members involved. One of the requirements of GCP is that the sponsor establishes an independent data monitoring committee. The monitoring committee needs to assess at frequent intervals the progress of a clinical trial, the safety of data, and the critical efficacy endpoints. During these visits the reported trial data should be verifiable to the monitor from source documents, i.e. patient files, surgery reports, charting notes, nursing notes. Each participating site needs to be visited numerous times, making this a large, and time-consuming administrative activity, not only for the monitor, but also for the physicians involved. Additionally, monitoring is associated with high costs, especially when multiple international sites are included in the clinical trial.

A major difficulty of conducting a European multi-center study remains, despite the EU Clinical Trials Directive, that each country, and sometimes even different hospitals within the same country, requires separate approval of the study protocol by the local authorities. This implies that submission to the Ethics Committees and Competent Authorities needs to be repeated in each EU country for the same study. We have applied for approval to conduct our study to the involved authorities 14 times. On top of that, the procedures to obtain this approval also differ greatly between different EU countries. The linguistic problems in the communication with the local authorities of some of the countries, demanding correspondence in their own local language, hampered communication considerably. For instance, we were repeatedly asked to sign official documents and declarations, sometimes even with an obvious legal status, in the local language. Surprisingly, in most cases an English translation was not accepted, since in certain countries official documents will only be issued in their local language. Obviously, official documents need to be in a mutually understandable language and the sponsor cannot sign a contract in a language he does not understand. Next to these linguistic problems, most official documents still refer to several national laws of which we did not know the exact content.

What practical consequences did the new Directive have for our study? Two hospitals were excluded due to the delays and difficulties caused by the new requirements. The completion of the study was delayed for at least one year. The delays were for a large extent due to the new administrative procedures of the Directive. Also, additional funding needed to be obtained to cover the extra costs of the monitoring requirements. Last, but certainly not least, the substantially increased administrative burden has undoubtedly reduced the enthusiasm and commitment of the physicians involved. In some cases even to the extent that they declared not to participate in these kind of studies again in the future.

\section{The need for centralization}

Were the concerns regarding the new EU Clinical Trials Directive legitimate? The answer is clearly: yes. The Directive has created many additional burdens for the conduction of academic trials independent of medical industry, while it did not meet the primary objective of harmonizing and simplifying the legislation in the Member States. It is now almost impossible for a group of physicians to conduct a European multi-center study independent of the industrial organizations and 
infrastructures. Clearly, this dependence is not desirable and it should be possible for surgeons and physicians to conduct studies independently.

The goal of the Directive to harmonize the legislation concerning clinical trials throughout the EU, was desirable, not only to strengthen Europe's economy by creating an internal common market, but also for European non-commercial research to be globally competitive. This legislation should guarantee the rights, safety and well-being of trial subjects, and insure that the results of the clinical trials are credible and reliable. It is obvious that the ethical and scientific quality should be verifiable to judging authorities and that this demands provision of sufficient information to these authorities. The information being requested, however, should bear relation with its purpose. Under the new Directive, application forms have grown to the size of books, carrying a message of general distrust of physicians, and it overlooks the fact that it is also in the best interests of the physicians to comply with demanded quality standards. The currently increased administrative requirements are inversely correlated to the physicians' enthusiasm to conduct independent clinical trials. In order to avoid that the research agenda in the future will be dictated by the medical industry and to preserve the unique role of independent research, the load of the paperwork to physicians, while conducting such a study, should diminish significantly.

Despite the new Directive, separate approval from each national authority is still required before a clinical trial can start. This, in combination with a lack of uniformity in the procedures and communication in a mutually understandable langue, make conduction of clinical trials a needlessly laborious and frustrating experience. It is a missed opportunity of the European Commission that they did not promote centralization of approval procedures, meaning that one central European authority to give approval for all Member States involved. This should not only be a central Ethics Committee that approves the trial for all European countries, but a central organ that also provides the authorization for all Competent Authorities involved. This would have significantly contributed in simplifying and harmonizing the legislation regarding clinical trials.

We believe that the professional organizations of the European physicians and surgeons should make efforts to facilitate non-commercial studies and put pressure on political authorities to reduce the administrative requirements concerning such trials. One important aspect in achieving this, is the implementation of central authority for application of trials, that applies in all Member States.

Acknowledgments We greatly acknowledge all participating surgeons in our trial for their understanding and patience during the encountered administrative difficulties: Dr. P. Bartolozzi, Universita' degli studi Di Verona, Verona, Italy; Dr. C. Garcia-Fernandez, Hospital Clinico San Carlos, Madrid, Spain; Dr. E. Gay, Hopital La
Tronche, Grenoble, France; Dr. F. Gossé, Annastift e.V., Orthop. Rehabilitationszentrum, Hannover, Germany; Dr A. Golash, Royal Preston Hospital, Preston, United Kingkom; Dr. E. Guerado, Hospital Costa Del Sol, Malaga, Spain; Dr. D. Prestamburgo, Ospedale di Circolo, Varese, Italy; Dr. L. Rillardon, Hopital Beaujon, Paris, France; Dr. N. Specchia, Ospedale Umberto I, Ancona, Italy; Dr. J. van Susante, Ziekenhuis Rijnstate, Arnhem, The Netherlands; Dr. M. Vahldiek, Auguste-Viktoria-Klinik Bad Oeynhausen e.V., Bad Oeynhausen, Germany; Dr. N. Verschoor, Jeroen Bosch Ziekenhuis, Den Bosch, The Netherlands.

Conflict of interest statement We declare that we have no conflict of interest.

Open Access This article is distributed under the terms of the Creative Commons Attribution Noncommercial License which permits any noncommercial use, distribution, and reproduction in any medium, provided the original author(s) and source are credited.

\section{References}

1. Anonymous (2001) Is the university-industrial complex out of control? Nature 409(6817):119

2. Anonymous (2003) Who's afraid of the European clinical trials Directive? Lancet 361(9376): 2167

3. Bodenheimer $\mathrm{T}$ (2000) Uneasy alliance-clinical investigators and the pharmaceutical industry. N Engl J Med 342(20):15391544

4. Directive 2001/20/EC of the European Parliament and of the Council of 4 April 2001 on the approximation of the laws, regulations and administrative provisions of the Member States relating to the implementation of good clinical practice in the conduct of clinical trials on medicinal products for human use. Official J Eur Communities 2001, L121:34-44

5. Friedberg M, Saffran B, Stinson TJ, Nelson W, Bennett CL (1999) Evaluation of conflict of interest in economic analyses of new drugs used in oncology. JAMA 282(15):1453-1457

6. Melander H, Hlqvist-Rastad J, Meijer G, Beermann B (2003) Evidence b(i)ased medicine-selective reporting from studies sponsored by pharmaceutical industry: review of studies in new drug applications. BMJ 326(7400):1171-1173

7. Morice AH (2003) The death of academic clinical trials. Lancet 361(9368): 1568

8. Moulton B (2004) Save European research campaign. BMJ 328(7434): 286

9. Remuzzi G, Schieppati A, Boissel JP, Garattini S, Horton R (2004) Independent clinical research in Europe. Lancet 364(9446): 1723-1726

10. Schieppati A, Remuzzi G, Garattini S (2001) Modulating the profit motive to meet needs of the less-developed world. Lancet 358(9293):1638-1641

11. Stelfox HT, Chua G, O'Rourke K, Detsky AS (1998) Conflict of interest in the debate over calcium-channel antagonists. N Engl J Med 338(2):101-106

12. Trouiller P, Olliaro P, Torreele E, Orbinski J, Laing R, Ford N (2002) Drug development for neglected diseases: a deficient market and a public-health policy failure. Lancet 359(9324): 2188-2194

13. Vandendael K (2004) Challenges of The Clinical Trial Directive for non-commercial cinical trials. Newsletter of Federation of European Cancer Societies. 27-2-2004. Ref Type: Internet Communication

14. Woods K (2004) Implementing the European clinical trials directive. BMJ 328(7434):240-241 